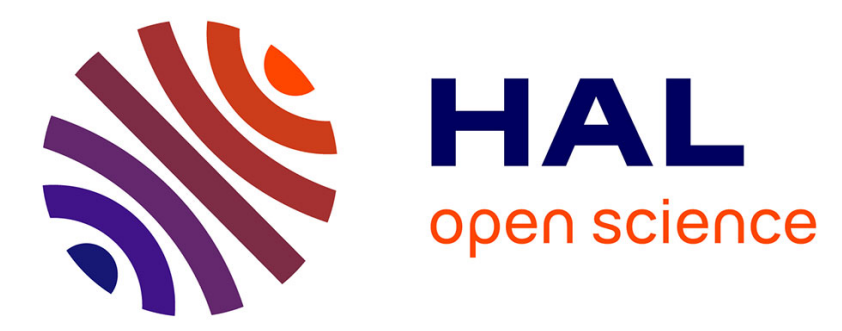

\title{
Individual signature in the most common and context-independent call of the Rook (Corvus frugilegus)
}

Benjamin Benti, Charlotte Curé, Valerie Dufour

\section{To cite this version:}

Benjamin Benti, Charlotte Curé, Valerie Dufour. Individual signature in the most common and context-independent call of the Rook (Corvus frugilegus). Wilson journal of ornithology, 2019, 131 (2), pp.373-381. 10.1676/18-41 . hal-02395415

\section{HAL Id: hal-02395415 https://hal.science/hal-02395415}

Submitted on 11 Dec 2020

HAL is a multi-disciplinary open access archive for the deposit and dissemination of scientific research documents, whether they are published or not. The documents may come from teaching and research institutions in France or abroad, or from public or private research centers.
L'archive ouverte pluridisciplinaire HAL, est destinée au dépôt et à la diffusion de documents scientifiques de niveau recherche, publiés ou non, émanant des établissements d'enseignement et de recherche français ou étrangers, des laboratoires publics ou privés. 


\section{The Wilson Journal of Ornithology Individual signature in the most common and context-independent call of the Rook (Corvus frugilegus) \\ --Manuscript Draft--}

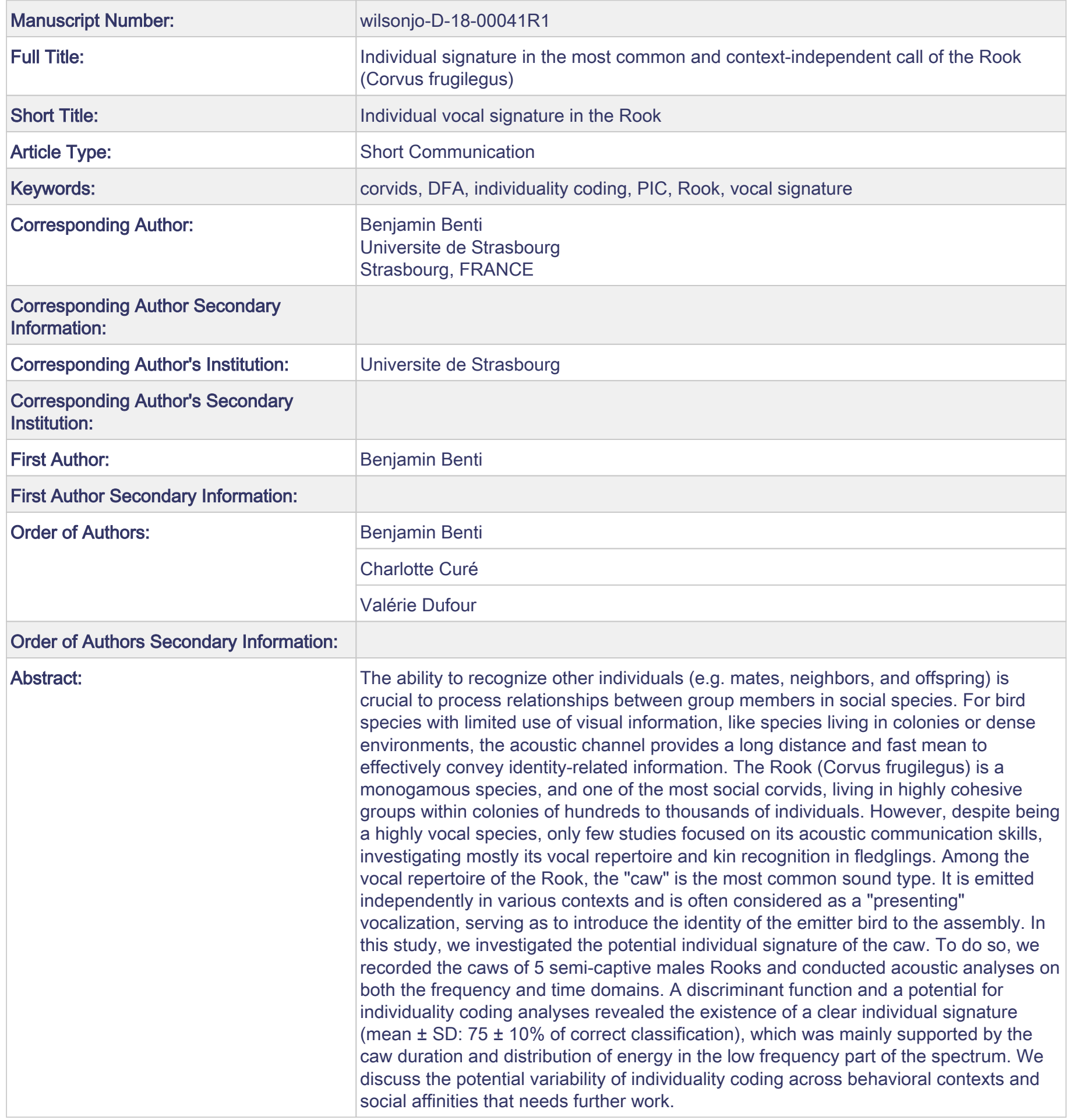


RRH: Short Communications

LRH: Benti et al.

\section{Individual signature in the most common and context-independent call of the Rook (Corvus frugilegus)}

Benjamin Benti ${ }^{1,2,3,4,6}$, Charlotte Curé $e^{3,5}$, and Valérie Dufour ${ }^{4,5}$

${ }^{1}$ Department of Biology, École Normale Supérieure de Lyon, 46, allée d'Italie 69364 Lyon Cedex 07 (France)

${ }^{2}$ Current address: University of Strasbourg, 4, rue Blaise Pascal CS90032 F-67081

Strasbourg Cedex (France)

${ }^{3}$ Current address: Cerema-Ifsttar, UMRAE, Laboratory of Strasbourg, Acoustics group, 11, rue Jean Mentelin 67035 Strasbourg Cedex 2 (France)

${ }^{4}$ Current address: CNRS, Délégation Alsace, MOY1000, Cognitive and social ethology team, 23, rue du Loess 67200 Strasbourg (France)

${ }^{5}$ These authors contributed equally to this work

${ }^{6}$ Corresponding author: benjamin.benti@etu.unistra.fr

\section{Abstract}

2 The ability to recognize other individuals (e.g. mates, neighbors, and offspring) is crucial to 3 process relationships between group members in social species. For bird species with limited 4 use of visual information, like species living in colonies or dense environments, the acoustic 5 channel provides a long distance and fast mean to effectively convey identity-related 6 information. The Rook (Corvus frugilegus) is a monogamous species, and one of the most 7 social corvids, living in highly cohesive groups within colonies of hundreds to thousands of 8 individuals. However, despite being a highly vocal species, only few studies focused on its 
9 acoustic communication skills, investigating mostly its vocal repertoire and kin recognition in fledglings. Among the vocal repertoire of the Rook, the "caw" is the most common sound type. It is emitted independently in various contexts and is often considered as a "presenting" vocalization, serving as to introduce the identity of the emitter bird to the assembly. In this study, we investigated the potential individual signature of the caw. To do so, we recorded the caws of 5 semi-captive males Rooks and conducted acoustic analyses on both the frequency and time domains. A discriminant function and a potential for individuality coding analyses revealed the existence of a clear individual signature (mean \pm SD: $75 \pm 10 \%$ of correct classification), which was mainly supported by the caw duration and distribution of energy in the low frequency part of the spectrum. We discuss the potential variability of individuality coding across behavioral contexts and social affinities that needs further work.

Key words: corvids, DFA, individuality coding, PIC, Rook, vocal signature.

Intra-specific communication is involved in most vital functions of animals' life and can be supported by one or usually more sensory channels (Witzany 2014). In birds, the visual and the acoustic channels are the two main sensory modalities used to communicate (Marler and Slabbekoorn 2004). When visual information is scarce or unavailable, acoustic signals can support the most reliable cues to effectively convey information (Curé et al. 2009). This can be the case in monomorphic species for which individuals share similar body size and feather coloration, or in particular ecological conditions such as in dark or crowded environments (e.g. forest habitats, bird colonies) as well as in constraining social environments (e.g. highly mobile species where animals need to communicate at distance). Bird vocalizations are associated to a range of social interactions. For example, bird songs can be used in a breeding context to attract a sexual partner and repel potential competitors (Kroodsma and Byers 1991), and in Chicks, begging calls are produced to solicit parents for feeding (Klenova 
particular element of the environment, such as the alarm call that can signal the presence and identity of a predator (Suzuki 2015). Last but not least, one of the most important messages conveyed by bird acoustic signals is information about the sender identity (e.g. its species, gender, age, hierarchical status, and individual identity), facilitating recognition at different levels (Curé et al. 2009). Because individual recognition can be involved in many aspects of social life, it has been extensively studied in highly social species.

This is particularly true in birds, where individual vocal signature has been shown to support recognition at various levels such as in mate-mate, parent-offspring recognition (Curé et al. 2009), or in neighbor-stranger discrimination (Briefer et al. 2009). The ability to recognize individuals can be crucial for intra-group cohesion in species living in densely populated societies, like in seabird colonies for which the risk of confusion between individuals is high. In complex social societies (e.g. in corvid species), animals also need to discriminate among individuals in order to continuously maintain group cohesion and especially during reunion with their group members in fission-fusion societies. In this regard, corvids (e.g. crows, ravens, magpies, and jays) provides a good framework to address the potential of individual signaling in their vocalizations. Corvid species are monogamous and some species live in social groups (Clayton and Emery 2007) with a level of complexity in their societies that has often been compared to those of highly social mammals (Emery and Clayton 2004). Corvids are highly vocal species, thus likely to rely on acoustics as their primary sensory modality to communicate and convey information regarding individual identity. The ability to vocally identify an individual was demonstrated in juvenile Rooks (Corvus frugilegus) which can discriminate between siblings' and non-siblings' calls (Røskaft and Epsmark 1984), in Jungle Crows (Corvus macrorynchos) which can differentiate among the calls of familiar conspecifics (Kondo et al. 2010), and in Common Ravens (Corvus corax) which can discriminate among food calls from familiar and 
unfamiliar conspecifics (Szipl et al. 2015). Moreover, acoustic analyses of corvid calls

60

61

62 revealed a multi parametric individual signature supported by both temporal and frequency domain variables, which birds could potentially use to recognize their congeners (Kondo et al. 2010, Mates et al. 2015).

Compared to the other species of the genus Corvus, the Rook has been poorly studied in respect to its vocal repertoire and the potential for individuality coding in its vocalizations. Yet, the Rook is one of the most social corvid species (Clayton and Emery 2007), living all year long in highly cohesive groups that can temporarily merge with others (Boucherie et al. 2016). Mated pairs do not establish into territories and remain in a social group, which requires particularly reliable vocal signatures ensuring recognition between mates and among group members. To our knowledge, the only work conducted on the Rook vocal repertoire is the one from Røskaft and Espmark (1982), who described 13 distinct calls and 7 apparent context-dependent usages of the same call, the "caw". Among those contexts, males caw during the breeding season, once they return and get perched near their nest. Since females mostly remain in the nests during incubation and males continuously move away and towards the nest to bring food to their partner, this caw could be crucial for the male to announce its presence to the mate or other group members throughout the breeding season (Røskaft and Espmark 1982).

Some studies investigated vocal individual signatures in context-specific calls of corvids, such as calls produced in a feeding context to attract conspecifics to a food source or to secure access to the food by repelling other birds (Boeckle et al. 2012), but there was no such acoustic analysis demonstrating the use of individual signatures in broadly used and context-independent calls. Here, we performed an acoustic analysis to investigate the potential for individuality coding in the most produced Rook call type, the caw, for which we suspected a role in recognition with other group members over a broad range of contexts. To 
do so, we recorded the caws of 5 male Rooks reared in semi-captivity and assessed potential inter-individual differences among a range of acoustic parameters measured in the frequency and time domains.

\section{Methods}

\section{Study animals and acoustic recordings}

We obtained acoustic recordings from 5 semi-captive male adult Rooks housed in an outdoor aviary (17 x 9 x $3.6 \mathrm{~m}$ ) with 7 other birds ( 3 males and 4 females). All 5 birds (named B, K, $\mathrm{N}, \mathrm{O}$, and $\mathrm{T}$ ) were fledglings fallen from the nest in 2005-2006 and hand-reared together in the aviary since. $\mathrm{K}$ and $\mathrm{O}$ were each involved in a pair with a female. $\mathrm{T}$ was paired with a male. $\mathrm{B}$ and $\mathrm{N}$ were single, but $\mathrm{B}$ was part of a triad including $\mathrm{K}$ and its female. It took part in nest building and would sometimes attempt copulation with K's female. The 5 birds could be clearly identified based on individual distinctive features (colored ring on each leg). We recorded dominance status and level of affinity between individuals (see Boucherie et al. 2016 for more information on group history and inter-individual relationships). The aviary was equipped with several wooden perches and located in a quiet green space of the campus of Strasbourg University (France). Birds were fed once a day and could access water and food ad libitum.

We recorded the calls and associated behavioral context during the breeding periods (Feb to May) of 2014 and 2015, using a Sennheiser ME67 directional microphone (frequency response: 50-20,000 Hz +/- $2.5 \mathrm{~dB}$ ) and a Zoom H4 recorder (sampling frequency: $48 \mathrm{kHz}$ ). We performed two 30 to $90 \mathrm{~min}$ recording sessions every week, randomly distributed between 08:00 $\mathrm{h}$ and 18:00 $\mathrm{h}$ (local time). Before each session, the experimenter sat quietly outside the aviary for about $15 \mathrm{~min}$ without moving before starting the recording and behavioral data collection, thus ensuring that the recorded vocalizations were not triggered by 
experimenter arrival. During each session, the observer was directly entering data about the time, sender identity, and behavioral context of the sound production; using Prim8 software (McDonalds and Johnson 2014) and an Android tablet.

\section{Acoustic analysis}

The caw of the Rook sounds "harsh" to the human ear. It has a roughly $1-2 \mathrm{kHz}$ frequency band with no clear harmonics, a heterogeneous repartition of the energy spectrum, and lasts 0.2 to $0.7 \mathrm{~s}$ (Røskaft and Espmark 1982). For the analysis, we selected the caws that showed no overlap with other bird's vocalizations or any noise in the environmental surroundings. Rooks can produce structurally similar caws with or without clear functional contexts (duets, before feeding a female, in response to another Rook's vocalization, etc.). We only focused on the caws emitted spontaneously outside a functional recognizable context, when the male was perched on its own, thus avoiding the detection of any acoustic signature related to the caws' context of emission. Moreover, because energy features can vary depending on sound propagation constraints, only the caw that were recorded at a maximum range of $8 \mathrm{~m}$ and without obstacles between the emitter and the microphone were selected for analysis.

The selected caws were filtered with a high-pass band filter at $300 \mathrm{~Hz}$ in order to remove background noise. Five acoustic features were measured in both time and frequency domains. The duration of the caws was measured on the amplitude envelope (Fig. 1). For most analyzed caws, there were no clear visible harmonics throughout the total call length and the fundamental frequency was difficult to determine. The average minimum frequency $\left(F_{\min }\right)$ was measured from the power spectrum as the first detected spectral peak (Hanning window, FFT length: 2048, threshold for spectral peak detection: $-15 \mathrm{~dB}$ ). To assess parameters related to the energy distribution, the frequency of maximal amplitude (FMA), 
and the frequency at the upper limit of the first and second quartiles of energy (abbreviated $F_{25}$ and $F_{50}$, respectively) were measured on the power spectrum (Fig. 1).

Acoustic analyses were performed using the "Seewave" package (Sueur et al. 2008) in R software v.3.4.1 (R Core Team 2017).

\section{Assessment of caw individual signatures}

In order to assess whether sender identity can be assigned based on acoustic features, a discriminant function analysis (DFA) was conducted on measured acoustic parameters. DFA requires similar group sizes, the absence of correlation between variables, and a normal distribution of variables within the groups. We achieved the homogeneity of group sizes by selecting similar numbers of calls for each individual at random. $\mathrm{N}$ produced fewer high quality caw calls than the other individuals and was the deciding factor in choosing the number of calls per individuals. We selected 15 high quality caw calls for $\mathrm{B}, \mathrm{K}, \mathrm{O}$, and $\mathrm{T}$, and 12 such calls for $\mathrm{N}$. We performed a principal component analysis (PCA) and removed correlated variables from the dataset to ensure the absence of correlation between acoustic features. We ran the DFA on the resulting uncorrelated variables instead of the PCA components, in order to ease the interpretation of further results (Curé et al. 2009). We did not necessarily met the normality criterion (Shapiro-Wilk test), but still performed the DFA given the robustness of the procedure.

A DFA was considered successful at assigning sender identity to the caws when more than $70 \%$ of the calls were attributed to the actual emitter. We validated the DFA through a jack-knife procedure; one by one, we removed the samples from the dataset, ran a DFA, and checked if the missing call was correctly sorted when it didn't account for the linear discriminants (LD). 

validated), we investigated which parameters supported the individual vocal signature. We calculated the potential for individuality coding (PIC) of each acoustic feature as follows (Robinson et al. 1993):

$$
P I C=C V_{b} / \text { mean }\left(C V_{i}\right)
$$

Where $C V_{b}$ is the coefficient of inter-individual variation and $C V_{i}$ are the coefficients of intraindividual variation, both measured as:

$$
C V=100\left(1+\frac{1}{4 N}\right) \frac{S D}{\text { mean }}
$$

Where $N$ is the sample size, mean and $S D$ the mean and standard deviation of the feature.

Parameters with a PIC higher than 1, i.e. with a within individual variation smaller than the inter-individual variation, can be interpreted as individual-specific (Robinson et al. 1993, Curé et al. 2009). We performed Kruskal-Wallis tests on these parameters to check whether inter-individual differences confirmed the PIC value. Package "MASS" (Venables and Ripley 2002) was used for the DFA and package "car" (Fox and Weisberg 2011) for data visualization. Significance level was set at 0.05 for all tests.

\section{Results}

171 The PCA performed on all acoustic features detected that the $\mathrm{F}_{25}$ and the $\mathrm{F}_{50}$ were strongly correlated. We chose to keep the $\mathrm{F}_{25}$ for further analyses, as low frequencies are less sensitive than high frequencies to emitter-distance variation. We ran the DFA using the following variables: duration of the call, FMA, $F_{25}$, and $F_{\text {min }}$. 

calls between individuals. Inter-individual differences in energy parameters were more difficult to detect visually (see Fig. 2 for an example spectrogram of each individual's caw). The DFA applied to the calls of 5 male Rooks indicated a significant difference across individuals (Wilk's $\lambda=0.07524, \mathrm{~F}_{16,196}=16.33, P<0.001$ ). The jack-knife validation procedure classified on average $75 \%$ (mean \pm SD: $75 \pm 10 \%$ ) of the calls correctly (Tab. 1 ). The most identifiable caller was $\mathrm{T}$ with $87 \%$ of caws correctly sorted, and the least identifiable was $\mathrm{O}$ with $60 \%$ of correct classification. Individuals $\mathrm{B}, \mathrm{K}$, and $\mathrm{N}$ showed intermediate values, with respectively 73,80 , and $75 \%$ of caws correctly assigned (Fig. 3). The DFA misclassified some caws within and between both pairs of individual N-O (6 misclassifications) and B-K (3 misclassifications), whereas no other bird was mistaken for $\mathrm{T}$.

Only the first linear discriminant (LD) of the DFA had an eigenvalue superior to 1 and accounted for $75 \%$ of the inter-individual variation. The LD1 was mostly driven by the $\mathrm{F}_{25}$ and the duration of the caws (Tab. 2).

The PIC values of the variables confirmed the DFA results. Indeed, the duration of the caw, the $\mathrm{F}_{25}$, and the $\mathrm{F}_{50}$ had a PIC higher than one, whereas the FMA and the $\mathrm{F}_{\text {min }}$ had a PIC inferior to 1 (Tab. 3). Inter-individual differences in call duration, $F_{25}$, and $F_{50}$ were also detected by Kruskal-Wallis test (Tab. 3). vocal signature of the Rook.

\section{Discussion}


In the present study, we conducted an acoustic analysis of the caws of 5 male Rooks and showed that the individuals were distinctive based mainly on the duration and the low frequency spectral energy distribution.

Our work highlighted the existence of an individual vocal signature in the caw call of the Rook. However, further work is required to investigate whether Rooks are capable of using such individual vocal signatures to recognize each other. Indeed, we focused on the sender's side of individuality and showed that Rooks produced individually specific caw calls. To test the ability of reveiver Rooks to recognize this individual signature, we should conduct playback experiments (Curé et al. 2016). We would need evidence that Rooks react differently to the broadcasted calls of different individuals.

Compared to other studies in corvids, we used a limited number of acoustic parameters (5 in our study) and we excluded measures of the fundamental frequency, which could not be clearly identified given the noisy structure of the Rooks' caws. Kondo et al. (2010) and Yorzinski et al. (2006), for instance, used respectively 24 and 20 measured acoustic features in the caws of the Jungle Crows and of the American Crows (Corvus brachyrhynchos). In both studies, individual call signature involved the duration and specific frequency values measured on the fundamental frequency. Here, we showed that both spectral energy distribution and duration parameters carried sufficient information to sort individuals, making the individual signature a multi-parametric feature of the caw. Therefore, this coding strategy based on different parameters appears to be a common mean in corvids and other colonial birds to secure information transfer from the emitter to the receiver in the noisy environment of the colony (Aubin and Jouventin 2002, Curé et al. 2009). As underlined by Tibbets and Dale (2007), there are numerous potential benefits associated with sender identity signaling. On one hand, it may reduce risks of inbreeding and aggressive interactions 
with conspecifics. On the other hand, it may facilitate kin selection and decision making for trade-offs such as between food competition and cooperation.

In American Crows though, individual discrimination was less clear when several contexts for cawing were considered (Mates et al. 2015), but could be still achieved with 65\% of success when focusing on alarm calls only (Yorzinski et al. 2006). The authors acknowledged that the acoustic structure of the caws could show variability (in duration for example) depending on the context of emission. In crows, different contexts can elicit the production of similar types of calls, with potential differences in the temporal structure of call emission, such as in the amplitude or in the repetition rate of the caws.

In our study, we deliberately focused on caws produced spontaneously with no clear functional context to avoid any variability depending on a particular context of emission and showed a clear individual signature. Given the diversity of contexts in which the caw can be used in Rooks, further investigation is needed to assess whether a contextual signature exists in the caw. Individuals might also differ based on other aspects of their vocal production: like American Crows, they may differ in the temporal pattern of successive cawing (Thompson 1969, Richards and Thompson 1978). They may also have a characteristic repertoire of calls. Indeed, although the caw was the most common vocalization produced by the Rooks we studied, it was not as frequently produced by all the birds of the aviary and could even be absent of the repertoire. During the breeding season, the females' most frequent call was the begging call. Caw calls from females occurred but were too few, and their quality was too low (e.g. overlap within group calling events) to include females in the analysis. Thus, apart from the 5 males studied here, we could not gather enough caws of good quality from the other individuals of the aviary to integrate them in the analysis. Further studies should investigate whether similar individual signature also exists in the caw of the female Rook, and whether birds that do not produce the caw have an equivalent call type. 

allow individual identification, some individuals' caws were more alike than others (B-K and $\mathrm{O}-\mathrm{N}$ ). None of these birds are genetically related, but B is a close affiliate to $\mathrm{K}$ (together with K's mate they form a triad, Boucherie et al. 2016). $\mathrm{O}$ and $\mathrm{N}$ have shown high tolerance toward each other for years, as they build their respective nests in contact to each other's during the breeding season. Our sample size was too small to conclude further on the acoustic similarities of caws among birds according to their social affinities, but this was demonstrated in another study on Ravens (Enggist-Dueblin and Pfister 2002) showing acoustic similarities within pair and affiliates. Moreover, acoustic resemblances or shared elements between neighbors' vocal repertoire might be used as a group signature to discriminate neighbors from strangers in order to engage conflict only towards non-familiar individuals (Mackin 2005, Briefer et al. 2013). In our study, all birds were breeding in the same aviary (and so they were all familiar to each other), which is not adapted to elucidate this question. As other corvids, Rooks are territorial breeders and are surrounded by other nesting birds of the colony, making 261 the task to find their nest and partner back challenging. On the other hand, acoustic 262 distinction between neighbors might help to identify more easily one's partner from neighbors and to avoid nest confusion. An optimal balance between acoustic similarities and differences with neighbors should allow birds to discriminate neighbors from strangers and to identify their partners from proximate neighbors. Further studies exploring the degree of similarity of the vocal repertoire and acoustic features of the Rook's calls according to natal influences, late adulthood relationships, and physical distance with other breeders (neighbors versus strangers) are needed to explore these questions.

\section{Aknowledgments}


270

271

272

273

274

276

277

279

We would like to thank the students who took part in data collection and analysis: T Boelhy,

V Jourdain, C Laubu, C Lausecker, E Meaux, and C Schmitt. We are grateful to R Gayet for his review of the manuscript.

\section{Literature Cited}

Aubin T, Jouventin P. 2002. Localisation of an acoustic signal in a noisy environment: the display call of the King Penguin Aptenodytes patagonicus. Journal of Experimental Biology. 205: 3793-3798.

Boeckle M, Spizl G, Bugnyar T. 2012. Who wants food? Individual characteristics in Raven yells. Animal Behaviour. 84(5): 1123-1130.

Boucherie PH, Mariette MM, Bret C, Dufour B. 2016. Bonding beyond the pair in a monogamous bird: impact on social structure in adult Rooks (Corvus frugilegus). Behaviour. 153(8): 897-925.

Briefer E, Aubin T, Rybak F. 2009. Response to displaced neighbours in a territorial songbird with a large repertoire. Naturwissenschaften. 96: 1067.

Briefer E, Rybak F, Aubin T. 2013. The role of shared phrases in skylark song: true syntax or simple auditory object? Animal Behaviour. 86: 1131-1137.

Clayton NS, Emery NJ. 2007. The social life of corvids. Current Biology. 17(16): R652R656.

Curé C, Aubin T, Mathevon N. 2009. Acoustic divergence between two sympatric nocturnal burrowing petrels: the Yelkouan and the Cory's shearwaters. Biological Journal of the Linnean Society. 96: 115-134. 
Curé C, Mathevon M, Aubin T. 2016. Mate vocal recognition in the Scopoli's shearwater Calonectris diomedea: do females and males share the same acoustic code? Behavioural Processes 128: 96-102

Emery NJ, Clayton NS. 2004. The mentality of crows: convergent evolution of intelligence in corvids and apes. Science. 306(5703): 1903-1907.

Enggist-Dueblin P, Pfister U. 2002. Cultural transmission of vocalizations in Ravens, Corvus corax. Animal Behaviour. 64(6): 831-841.

Fox J, Weisberg S. 2011. An R companion to applied regression. $2^{\text {nd }}$. Thousand Oaks (CA): Sage.

Klenova AV. 2015. Chick begging calls reflect degree of hunger in three Auk species (Chaladriiformes: Alcidae). PLoS ONE. 10(11): e0140151

Kondo N, Izawa EI, Watanabe S. 2010. Perceptual mechanism for vocal individual recognition in Jungle Crows (Corvus macrorhynchos): contact call signature and discrimination. Behaviour. 147(8): 1051-1072.

Kroodsma DE, Byers BE. 1991. The function(s) of bird song. Integrative and Comparative Biology. 31(2): 318-328.

Mackin WA. 2005. Neighbour-stranger discrimination in Audubon's shearwater (Puffinus l. lherminieri) explained by a 'real enemy' effect. Behavioral Ecology and Sociobiology. 59:326-332.

Marler P, Slabbekoorn H. 2004. Nature's music. The science of birdsong. San Diego (CA): Academic Press/Elsevier. 
Mates EA, Tarter RR, Ha JC, Clark AB, McGowan KJ. 2015. Acoustic profiling in a complexly social species, the American Crow: caws encode information on caller sex, identity and behavioural context. Bioacoustics. 24(1): 63-80.

McDonald M, Johnson S. 2014. "There's an app for that": a new program for the collection of behavioural field data. Animal Behaviour. 95: 81-87.

R Core Team. 2017. R: a language and environment for statistical computing. Vienna (Austria): R Foundation for Statistical Computing.

Richards DB, Thompson NS. 1978. Critical properties of the assembly call of the common American Crow. Behavior. 64: 3-4.

Robinson P, Aubin T, Brémond JC. 1993. Individuality in the voice of the Emperor Penguin Aptenodytes forsteri: adaptation to a noisy environment. Ethology. 94(4): 279-290.

Røskaft E, Espmark Y. 1982. Vocal communication by the Rook Corvus frugilegus during the breeding season. Scandinavian Journal of Ornithology. 13(1): 38-46.

Røskaft E, Espmark Y. 1984. Sibling recognition in the Rook (Corvus frugilegus). Behavioural Processes. 9:223-223.

Sueur J, Aubin T, Simonis C. 2008. Seewave: a free modular tool for sound analysis and synthesis. Bioacoustics. 18: 213-226.

Suzuki TN. 2015. Assessment of predation risk through referential communication in incubating birds. Scientific reports. 5:10239

Szipl G, Boeckle M, Wascher CAF, Spreafico M, Bugnyar T. 2015. With whom to dine? Ravens' responses to food-associated calls depend on individual characteristics of the caller. Animal Behaviour. 99: 33-42. 
Thompson NS. 1969. Individual identification and temporal patterning in the cawing of Common Crows. Communications in Behavioural Biology. 4: 29-33.

Tibbets EA, Dale J. 2007. Individual recognition: it is good to be different. Trends in Ecology and Evolution. 22(10): 529-537.

Venables WN, Ripley BD. 2002. Modern Applied Statistics with S. $4^{\text {th }}$. New York (NY): Springer.

Witzany G. 2014. Biocommunication of animals. Dordrecht (Netherlands): Springer.

Yorzinski JL, Vehrencamp SL, McGowan KJ, Clark AB. 2006. The inflected alarm caw of the American Crow: differences in acoustic structure among individuals and sexes. The Condor. 108(3): 518-529.

\section{Figure captions}

Figure 1: Acoustic variables measured in a male caw of the Rook. Spectrogram (top panel) of the caw along with the indication of the relative amplitude (grey scale). Amplitude envelope (middle panel) showing the measure of the caw duration. Power spectrum of the caw (bottom panel) showing the detected spectral peaks: the regular cross indicates the $F_{\min }$ and the bold cross indicates the FMA. $F_{25}$ and $F_{50}$ were measured from the power spectrum and correspond to the frequency values below which the spectrum contains respectively 25 and $50 \%$ of the total energy.

Figure 2: Spectrogram and indication of the relative amplitude (grey scale) of one example caw of each individual B, K, N, O, and T (Hanning window, 2048 points, 25\% overlap).

Figure 3: Visual representation of the DFA results. This graph represents the values of the analyzed caws through the LD1 and LD2 (respectively on the $\mathrm{x}$ - and y-axis). The caws from 
$356 \mathrm{~B}$ are represented as squares, from $\mathrm{K}$ as circles, from $\mathrm{N}$ as triangles, from $\mathrm{O}$ as + crosses, and 357 from $\mathrm{T}$ as $\mathrm{x}$ crosses. Each individual is summarized by an ellipse with a different hatching, 358 which surrounds $70 \%$ of its calls. 
359 Table 1: Results of the jack-knife-validated classification of the caws by the DFA.

\begin{tabular}{|c|c|c|c|c|c|c|c|}
\hline DFA Class & & B & K & $\mathrm{N}$ & $\mathrm{O}$ & $\mathrm{T}$ & $\begin{array}{l}\text { Correct } \\
\text { classification } \\
(\%)\end{array}$ \\
\hline \multirow[t]{6}{*}{ Real Class } & B & 11 & 2 & 2 & 0 & 0 & 73 \\
\hline & $\mathrm{K}$ & 1 & 12 & 1 & 1 & 0 & 80 \\
\hline & $\mathrm{N}$ & 1 & 0 & 9 & 2 & 0 & 75 \\
\hline & $\mathrm{O}$ & 1 & 1 & 4 & 9 & 0 & 60 \\
\hline & $\mathrm{T}$ & 1 & 1 & 0 & 0 & 13 & 87 \\
\hline & & & & & & Total & 75 \\
\hline
\end{tabular}


361 Table 2: Results of the DFA applied on the caws and loadings of the 3 extracted LD. The 362 LD1 was the only extracted component of the DFA with an eigenvalue $>1$ with duration and $363 \quad F_{25}$ as the most representative variables (in bold).

\begin{tabular}{|c|c|c|c|}
\hline & Linear Dis & & \\
\hline Variable & LD1 & LD2 & LD3 \\
\hline Duration & 0.437722 & 0.592371 & -0.399456 \\
\hline $\mathrm{F}_{25}$ & -0.716319 & 0.327439 & -0.616106 \\
\hline FMA & -0.098303 & 0.088232 & -0.652831 \\
\hline$F_{\min }$ & -0.043263 & -0.789367 & -0.412623 \\
\hline Eigenvalue & 4.35425 & 0.882161 & 0.318782 \\
\hline $\begin{array}{l}\text { Variance explained } \\
\text { (cumulative \%) }\end{array}$ & 78 & 94 & 100 \\
\hline
\end{tabular}


365 Table 3: PIC values and Kruskal-Wallis tests for all 5 measured acoustic parameters.

$366 P$-values inferior to the significance threshold of 0.05 (in bold) indicate the parameters with a

367 potential for individuality coding.

\begin{tabular}{lllll}
\hline Variable & $\mathrm{CV}_{\mathrm{i}}$ & $\mathrm{CV}_{\mathrm{b}}$ & $\mathrm{PIC}$ & \multicolumn{1}{l}{ Kruskall-Wallis test } \\
& & & & $P$-value \\
\hline Duration & 8.918 & 13.346 & $\mathbf{1 . 4 9 7}$ & $<\mathbf{0 . 0 0 1}$ \\
$\mathrm{F}_{25}$ & 3.460 & 6.339 & $\mathbf{1 . 8 3 2}$ & $<\mathbf{0 . 0 0 1}$ \\
$\mathrm{F}_{50}$ & 5.420 & 8.348 & $\mathbf{1 . 5 4 0}$ & $<\mathbf{0 . 0 0 1}$ \\
FMA & 9.225 & 4.728 & 0.513 & N/A \\
F & 26.591 & 24.045 & 0.904 & N/A \\
\hline
\end{tabular}


Figure 1:
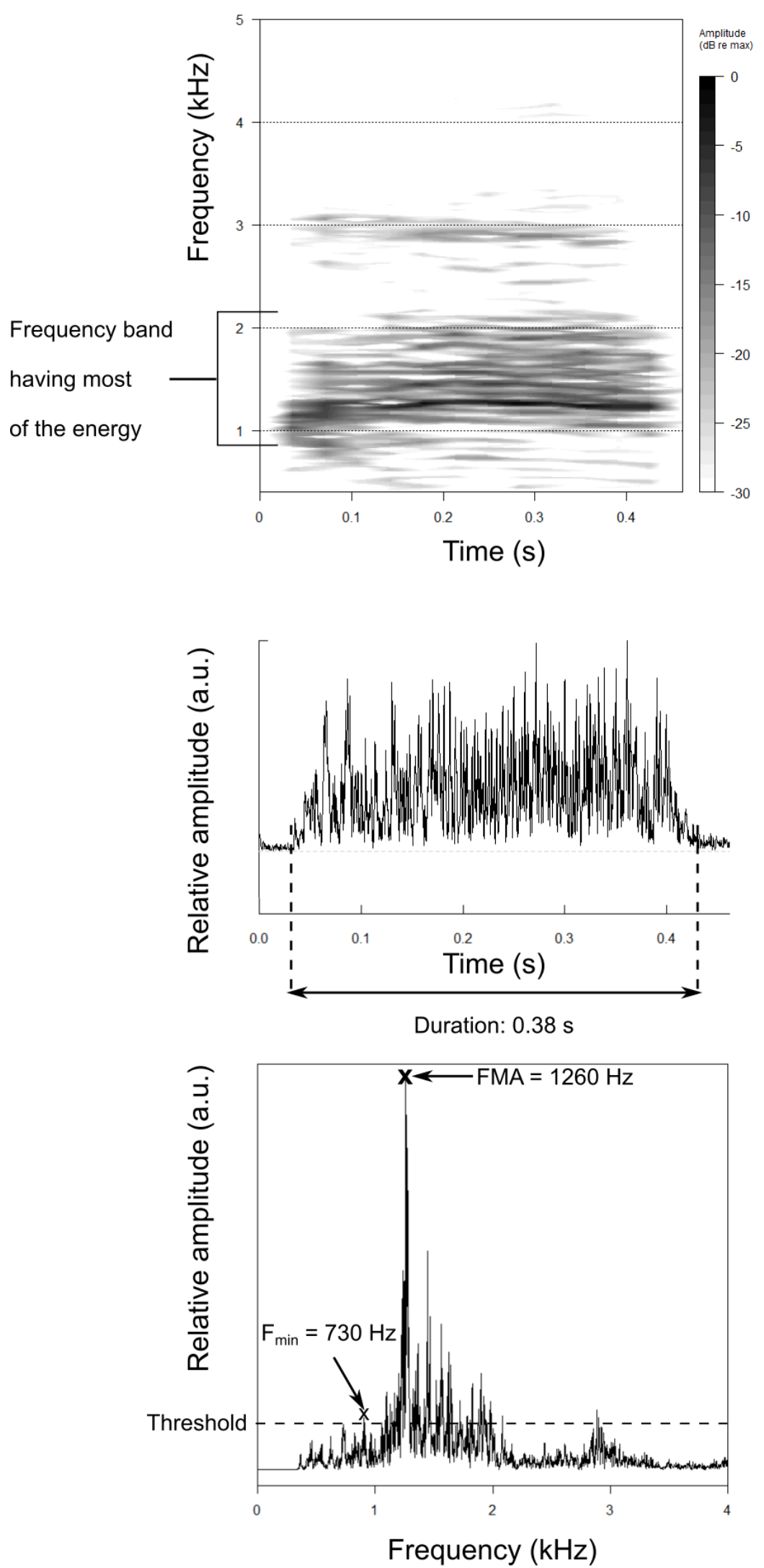
Figure 2:
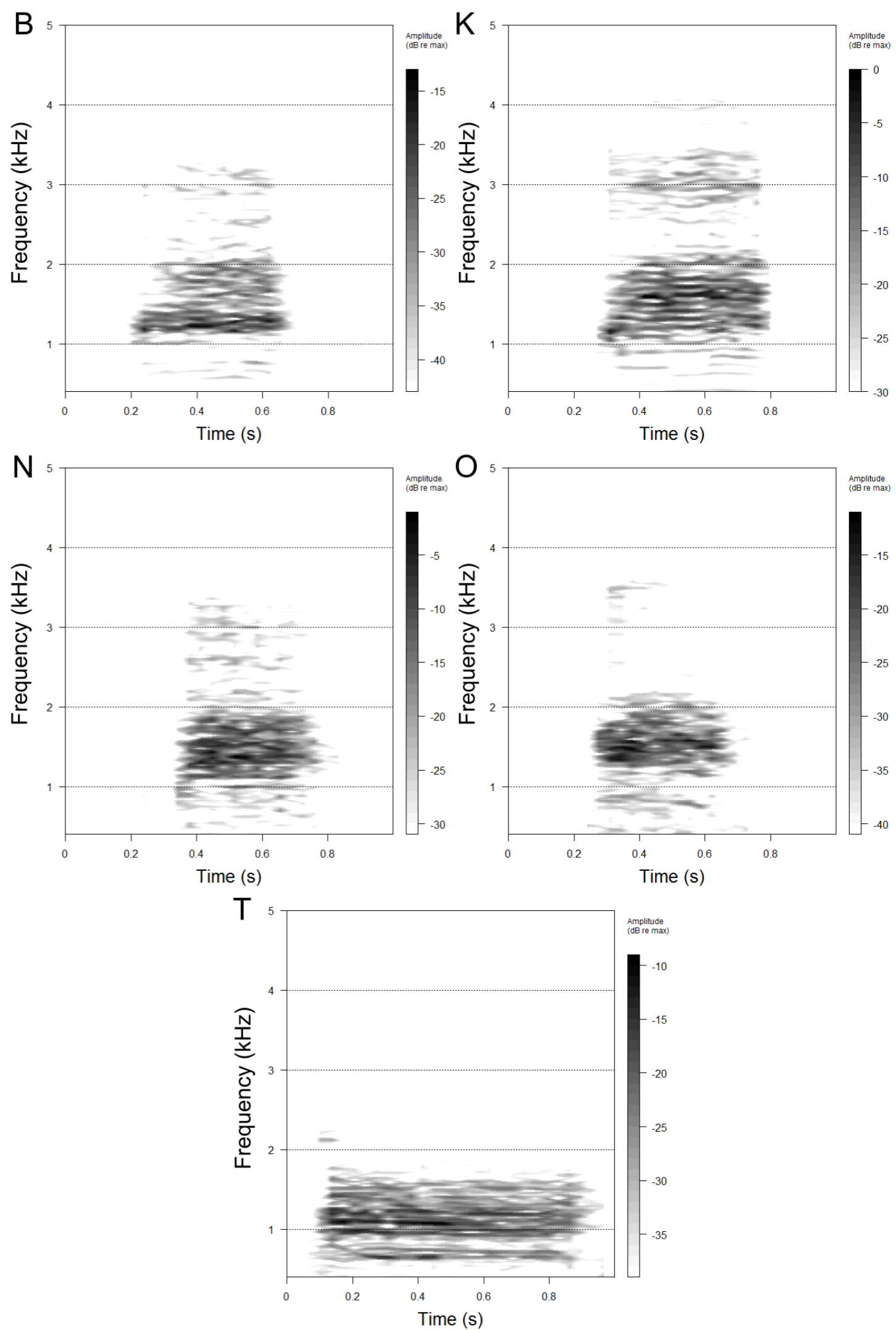
372 Figure 3:

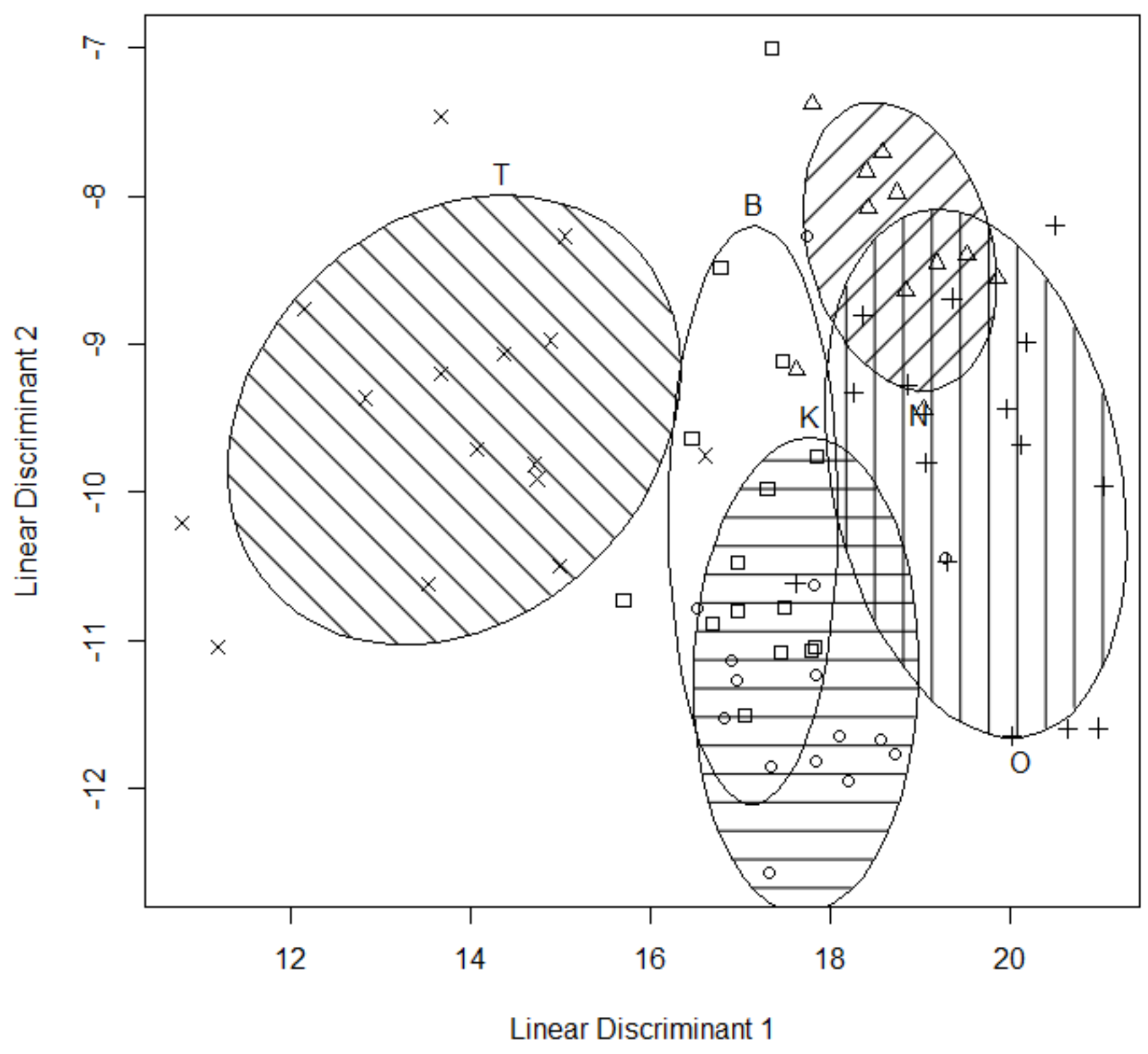



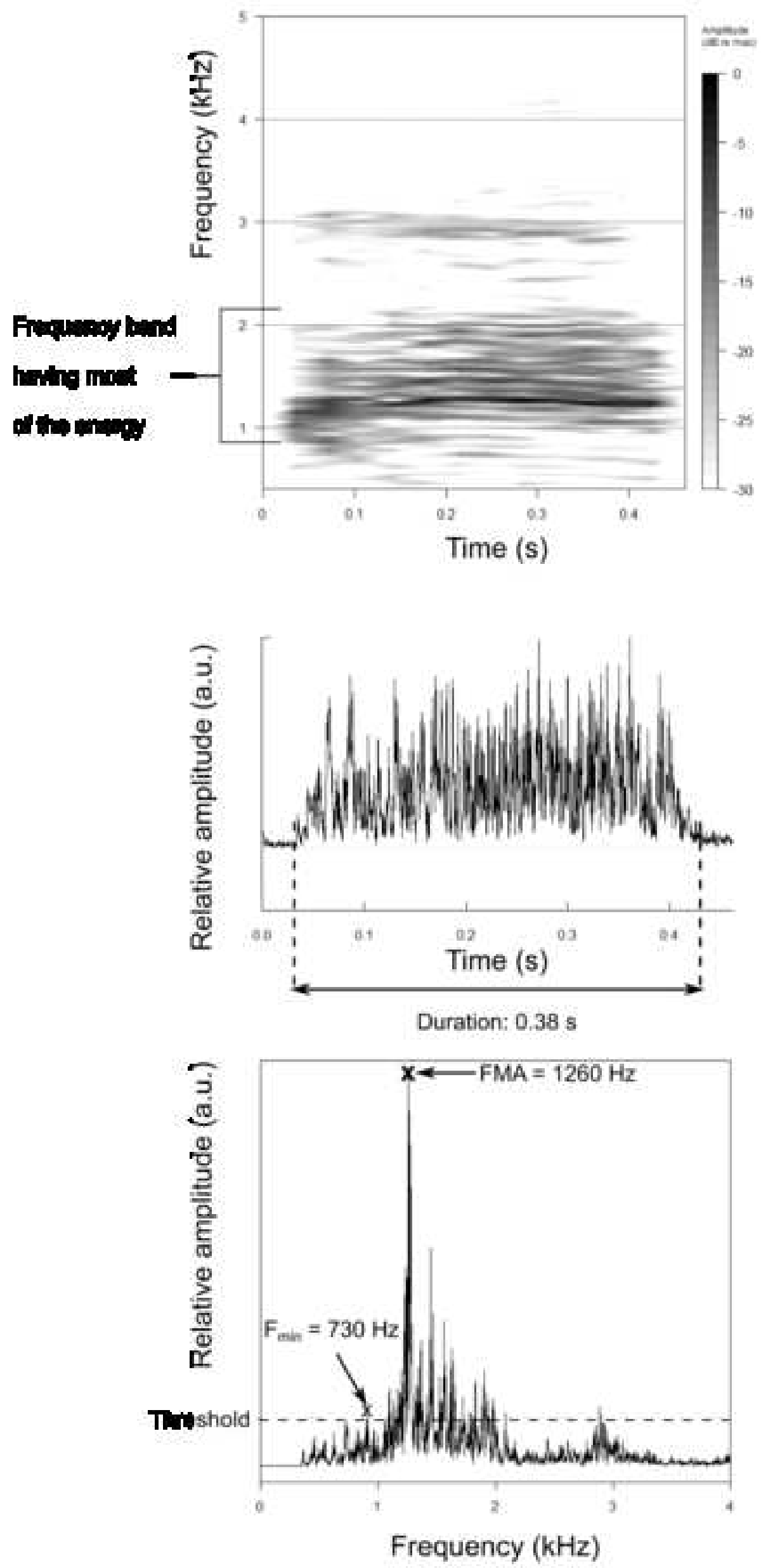

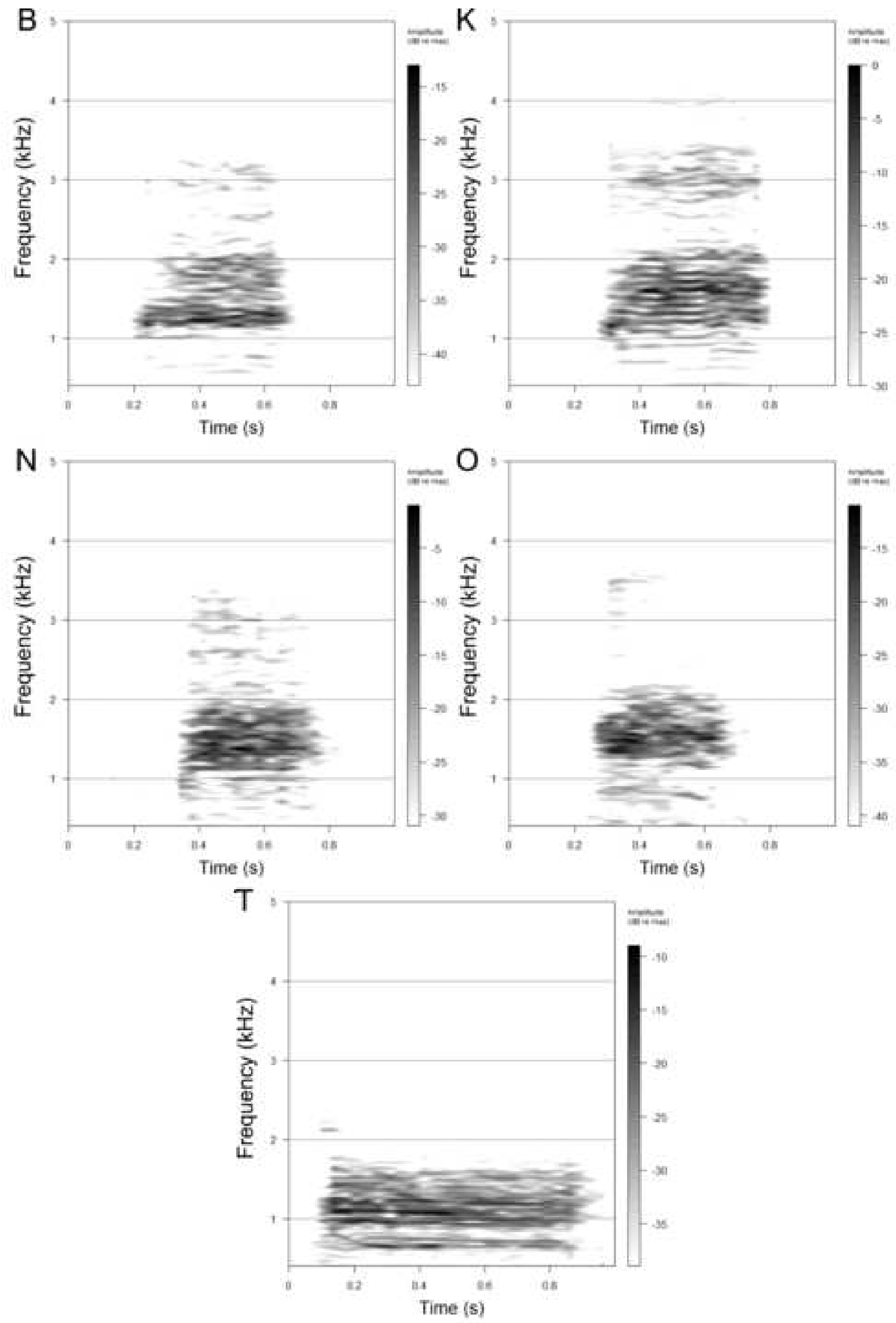


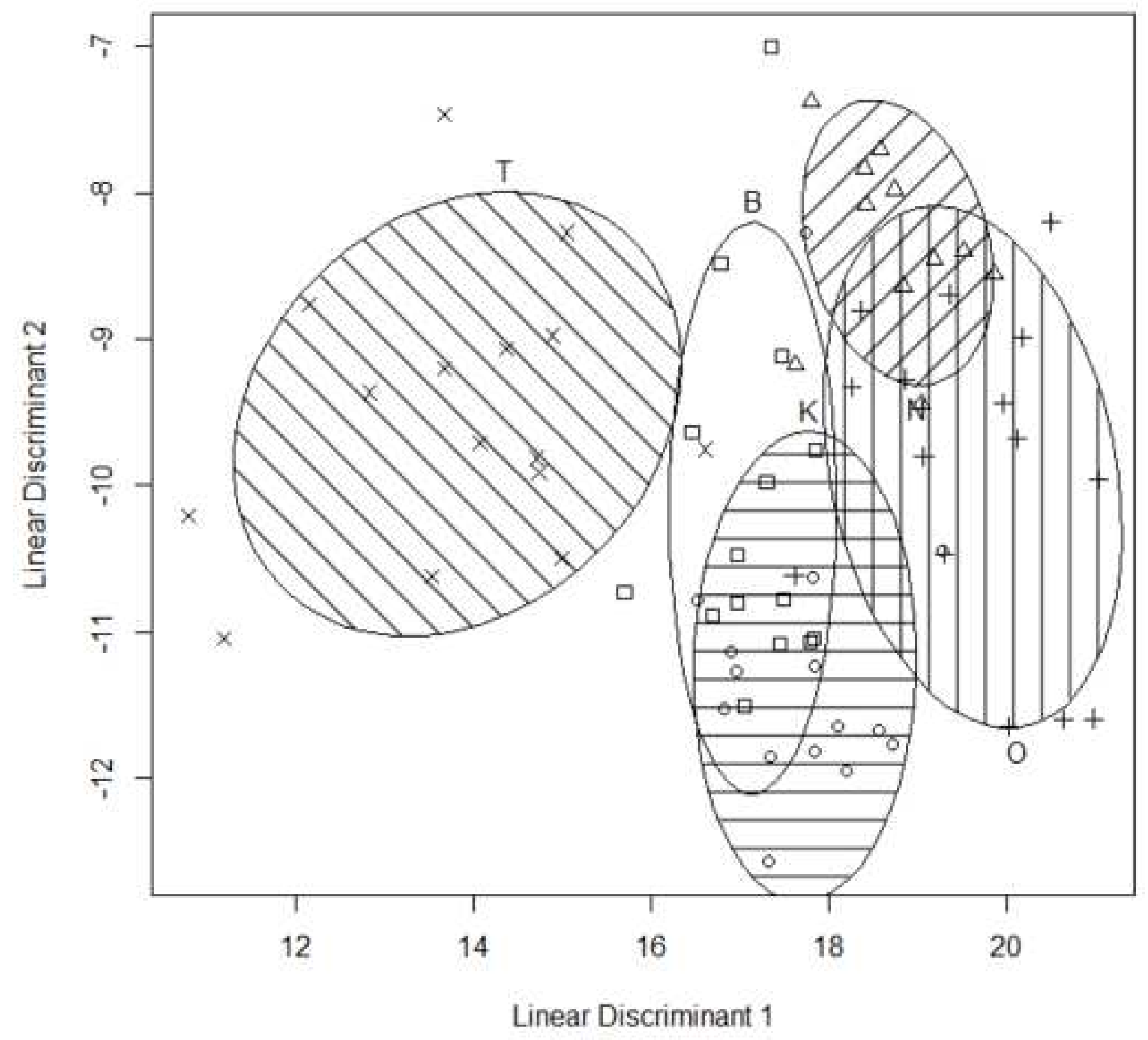

